CASO CLINICO

Rev. Chil. Pediatr, $69(5) ; 215-217,1998$

\title{
Intoxicación por carbamazepina con dos dosis de claritromicina: Reporte de un caso
}

\author{
Paula Araya H. '; Jacobo Cohen V.2 ; Carlos Silva R. '; Manuel Fruns Q.'
}

\begin{abstract}
Resumen
La :neracción entra carbamazepina y cla'tromicina na sido :ecientemenle reportada en lo literarura. Reportamos el caso de tn niño de 8 años, pontador de epilepsia, quer presentó una intoxicación por corbamazepi-a luego de cue se agregara clariromicina al tratomiento. Cespués de la segundo dosis del antib́ólico el pociente se mostró somno iento y con alaxia cerebelosa, derrosliandose uno imporlan'e elevación del nivel plasmálico de carbamazepira. El paciente recotró su condicion normal rópidomerle, luego de que se suspencierc el ontioiótico con la concomilante disminución del nivel piasmático de cnticonvulsivante. Se ciscuten las caracteristicas de esto interaccián de fómiriacos haciendo resaltar las carocierísticas del metabolismo de los niños cue hace especialmente imporante esta siluación clénico
\end{abstract}

(Palabras clave: corbamazepina, claritomicina. macró idos, interacción de drogas, intoxicación par drogas.)

\section{Intoxication by carbamazepin with a two-clarithromycin doses, clinical report}

Clarithromycin and corbamazepine interaction has been recently reporled in the lilerclure. Here we repori an unusual early clinical intoxication when carithronycir was added to corbamazepine in a 8 vea old boy who suffered from epilepsy. Trere was a h gh elevation of corbanazepine plosmo level associated with somnolence and cerebellar alaxia after the second dose of clorimromycin. The child recovered his nomal condition rap cily after the withdrawai ct the antibiotic, with no"malization of the plasmo level of carbamazepirie. We discuss the charactheristics of 1 e interaction of these rwo drugs anc we stress Ine speciai ceatures of the children me-abolism that moy accouril for this interaction.

(Key words: corbamazepine, clar Imomycin, macrolides, drug toxicily, crug interaction.i

La interacción entre carbamazepina y macrólidos, especialmente la eritromicina, ha sido reportada en la literatura. Tanto la carbamazepina como estos antibióticos son metabolizados a njvel hepático por la misma iscenzima del citocromo P450. Cuando ambos medicamentos son administrados concomitantemente existe una in. teracción inhibitoria que resulta en una elevación del nivel plasmático de carbamazepina. La aparición de nuevos macrólidos como la claritromicina ha motivado la evaluación formal de esta interacción ${ }^{1 \cdot 3}$.

1. Servicio de Neurología, Hospital Clínico de la Universidad de Chile José Joaquín Aguime.

2. Servicin de Infectologia. Hospital Luis Calvo Mackeлna.
La claritromicina es considerada el antibiótico de primera línea en las infecciones por $\mathrm{My}$ coplasma neumonía y es una de las primeras alternativas terapéuticas en las infecciones del tracto respiratorio alto, incluyendo otitis, sinusitis e incluso neumonías extrahospitalarias. Han sido reportados aproximadamente 10 casos en que el uso concomitante de claritromicina y carbamazepina resultó en una elevación del nivel plasmático de carbamazepina con signos clínicos de intoxicación ${ }^{2-4}$. La mayoría de estos casos eran adultos y la intoxicación clínica apareció tardíamente.

Presentamos un niño con una clara intoxicación por carbamazepina inusualmente precoz luego de que recibiera la segunda dosis de claritromicina indicada por una infección del tracto 
respiratorio. Dada la prevalencia de epilepsia en la infancia y la frecuente prescripción de clarjtromicina en esta edad, es posible esperar un aumento en la incidencia de la interacción entre carbamazepina y claritromicina. En Chile no conocemos reportes de esta interacción.

\section{Caso clínico}

Se presenta un niño de ocho años portador desde los 4 años de una epilepsia occipitat benigna. quien es referi. do por un cundro clínico caracterizado por tos, otalgia izqujerda, y fiebre de hasta $38.5^{\circ} \mathrm{C}$. El examen físico general mostraba signología compatible con neumopatía basal derecha $y$ enrojecimiento del tímpano izquierdo. El re. cuento de glóbulos blancos alcanzaba los $5000 / \mathrm{mm}$, con discreła desviación a izquierda y una velocidad de sedimentación de $15 \mathrm{~mm}$. La radiografía de tórax reveló uta neumonía basal derecha y el estudio con IgG para Mycoplastna neumonia fue positivo. Se le indicó claritromicina, $250 \mathrm{mg}$ cuda 12 horas como rerapia única. El paciente recibía, desde el diagnóstico de la epilepsia. carbamazepina como monoterapia desde hacía aproximadamente dos años en dosis de $300 \mathrm{mg}$ cada 8 horas $(30 \mathrm{mg} / \mathrm{kg}$ ). Su control anual de nivel plasmático, realizado un mes anıes del cuadro clínico actual, era de $10 \mu \mathrm{g} / \mathrm{ml}$ (8 a $12 \mu \mathrm{g} / \mathrm{ml}$ como rango terapéulico). Luego de 2.2 horns de iniciado el tratamiento y después de la segunda dosis de claritromicina, el paciente estaba somnoliento, disártrico, con dipłopia, nistagmus y clarr ataxia. En este momento se realizó un nivel plasmático del anticonvulsivante resultando $28 \mathrm{\mu g} /$ ml. Doce horas después de haber suspendido la terapin antihiólica y habiendo interrumpido una dosis de carbamazepina. el nivel plásmatico había disminuido a 10 $\mu g^{\prime}$ ml y se mantuyo en este rango luego de reiniciada la terapia anticonvulsivante (tabla).

EI paciente se encontraba alerta, sin ataxia y sin disyunción óculo motora. Lina semana después se encon- traba afebril. la radiografía de tórax demostraba regresión de la neumonía y su nivel plasmático de carbanazepina permanecía estable.

\section{Comentario}

La elevada prevalencia de epilepsia durante la infancia ${ }^{\mathrm{I}}$ determina la frecuente prescripción de carbamazepina en esta etapa de la vida. Por orra parte la claritromicina se ha convertido en un antibiólico de uso frecuente en las infecciones del tracto respiratorio alto y en neumopatías, haciendo posible el uso concomitante de estos dos fármacos.

La interacción entre carbamazepina y macrólidos está bien descrita para la eritromicina y se explica porque es la misma isoenzima del citocromo P450 quien metaboliza ambos tipos de fármacos. La claritromicina es metabolizada específicamente por la isoenzima CYP3A4, al igual que la carbamazepina ${ }^{2}$. La presencia de ambas drogas determina un bloqueo de la transformacion habitual de carbamazepina en su metabolito carbamazepina 10,11 epóxido, induciendo así una elevación de la razón carbamazepina/carbamazepina epóxidol-3. La elevación en esta razón resulta en una elevación del nivel plasmático de carbamazepina y la concomitante intoxicación clínica.

Nuestro paciente presentó signos de intoxicaciôn por carbamazepina con niveles plasmáticos clevados, luego de la administración de una segunda dosis de $250 \mathrm{mg}$ de claritromicina. Aunque la revisión de la literatura muestra reportes

\section{Tabla}

Evolución del nivel plasmático de carbamazepina postintroducción de claritromicina

\begin{tabular}{|c|c|c|c|}
\hline & $\begin{array}{c}\text { Nivel plasmático } \\
\text { de carbamazepina } \\
\qquad(\mu \mathrm{g} / \mathrm{ml})\end{array}$ & $\begin{array}{l}\text { Dosis de } \\
\text { carbamazeping }\end{array}$ & Síntomas \\
\hline Basal & 10 & 300 cada 8 horas & $(-)$ \\
\hline $\begin{array}{l}22 \text { h despues de iniciada la } \\
\text { claritromicina ( } 2 \text { dosis de } 250 \mathrm{mg} \text { ) }\end{array}$ & 28 & Sin dosis noeturna & $\begin{array}{l}\text { Somnolencia. } \\
\text { nistagmus. } \\
\text { diplopia, disartria }\end{array}$ \\
\hline $\begin{array}{l}\text { 12 h despues de la intermpción } \\
\text { de la claritronicina }\end{array}$ & 10 & $300 \mathrm{mg} c 0 \mathrm{da} 8$ horas & $(-)$ \\
\hline $\begin{array}{l}24 \text { h después de la interrupción } \\
\text { de claritromicina }\end{array}$ & 10 & $300 \mathrm{mg}$ cada 8 horas & $(-)$ \\
\hline
\end{tabular}


de intoxicación clínica por el anticonvulsivante aun reduciendo la dosis de este mientras se administra la claritromicina ${ }^{2 .}{ }^{4}$, no encontramos ningún reporte en que esto ocurriera tan precozmente. Debe tenerse en cuenta que todos estos reportes correspondian a la vida adulta.

Las dosis de carbamazepina indicadas en pediatría son significativamente mayores que en la vida adulta por las características del metabolismo hepático de los niños ${ }^{8.11}$; altas dosis de carbamazepina son rápidamente transformadas en su metabolito epóxido ${ }^{5 \cdot 8 .} 10$ manteniendo la razón carbamazepina/carbamazepina epóxido en niveles terapéuticos. Este hecho puede explicar que cuando se encuentra bloqueada la isoenzima CYP3A4 el valor de la razón se eleve rápidamente, pudiendo resultar en una intoxicación clínica, pues el numerador tiene inicialmente un valor alto.

El otro hecho que nos parece destacable es la rapidez de la recuperación clinica y de laboratorio con respecto de la carbamazepina lucgo de la suspensión de la claritromicina. Este fenómeno puede explicarse porque en la infancia la depuración de carbamazepina es mucho mayor que en la vida adulta ${ }^{8.11}$ lo que resulta en un rápido aclaramiento del fármaco luego de restituido su normal metabolismo.

Nos parece que considerando las características del metabolismo de la carbanazepina, el uso concomitante con claritromicina debe ser evitado. Otros macrólidos como la azitromicina podrían ser una mejor alternativa, aunque la lileralura no es categorica a este respecto ${ }^{9}$. Recientemente se ha introducido la oxcarbamazepina, anticonvulsivante que no es metabolizado a nivel del citocromo $\mathrm{P} 450$ y que por lo tanto no interactúa con los macrólidos y pudiera ser este otro argumento para su utilización en la vida pediátrica.

\section{Referencias}

1. Levy RH: Cytochrome $P 450$ isozymes and antiepileptic drug interactions. Epilepsia 1995; 36 (Suppl.5): 8. 13.

2. O'Connor NK. Fris $\mathrm{d}$ : Clarithromycin-carbamazepine interaction in a clinical setting J Am Fan Pract 1994; 7: 489-492,

3. Von Rosensteil NA. Adam D: Macrolide antibacterials. Drug Interactions of clinical significance. Drug Safety $1995 ; 13 ; 105-122$

4. Albani F, Riva R. Baruzzi A: Clarithromycin-carbamazepine interaction: A case report. Epilepsia 1993; 34: $161-162$.

5. Bourgeois BDF, Wad $N$ : Carbamazepine-10, 11-diol steady-state serum levels and rena! excretion during carbamazepin therapy in adults and children. Ther Drug Monit 1984; 6: 259-265.

6. Altafullat 1. Talwar D. Loewenson $R$, Olson $K$, Lockmun LA: Factors influencing serum levels of carbarnazepine and carbamazepine-10, 11 -epoxide in children. Epilepsy Res 1989; 4: 72-80.

7. Schoman JF. Elyas AA, Brett EM, Lascelles PT: Altered ratio of carbamazepin-]0, I - epoxide/carbamazepine in plassna of children: evidence of anticonvulsant drug interaction. Med Child Neurol 1984; 26: 749.7 .55 .

8. Levy RH, Kerr UB: Clinical Pharmacokinelics of carbamazepine. J Clin Psychiatry 1988: 49 (Suppl. J): $58-64$.

9. Rapeport WG. Dewland PM. Muirhead DC. Foster $P L$ : Lack of interaction between azithromicyn and carbamazepine. In Proceedings of the Brithish Pharmacological Society. London, 1991.

10. Lit $H$. Delgado MR: Influence of sex, age, wieght and carbamazepine dose in epileptic children. Ther Drug Monit 1994; 16: 469-476. 